\title{
Effects of noise on early development in the rat
}

\author{
COLLEEN S. SMILEY and W. A. WILBANKS \\ University of Georgia, Athens, Georgia 30602
}

\begin{abstract}
Rat pups, age 15 days, were exposed to an 80-dBA or a 100-dBA noise $(100 \mathrm{~Hz}$ centered at $8 \mathrm{kHz}$ ) for $3 \mathrm{~h} /$ day for 30 days. As compared with control animals, noise exposure was found to activate behavior, as seen by increased incidence of grooming, play, and locomotion, and decreased incidence of sleep. Behavioral habituation occurred during the periods of noise exposure but did not occur from day to day. No indication of a noise-induced stress reaction, as measured by changes in adrenal gland weight and stomach ulceration, was found.
\end{abstract}

Astrálága, Carvalho, and Jiminez (1975) have reported that mice exposed to a $90-\mathrm{dB}$ noise for either 3 or $8 \mathrm{~h} /$ day for 50 days (noise exposure started at either age 2 days or age 15 days) showed significantly smaller weight gains than control animals. In this paper, we examine some nonauditory effects of noise exposure on early postnatal physical and behavioral development in the albino rat (Rattus norvegicus). This animal was chosen because its physical and behavioral development has been well documented (Barnett, 1975; Bolles \& Wood, 1964; Slonaker, 1959; Small, 1899). Daily weight gain was taken as a measure of gross physical development. The effects of daily noise exposure on the following behaviors were assessed: grooming, locomotion, play, sleep, aggression, and emotionality (defecation). During the last 3 days of the experiment, defecation and locomotion in an open field were measured. The animals were then sacrificed, and their adrenal glands were weighed and their stomachs were examined for ulceration to determine if the noise acted as a stressor (Groh, 1966; Paré, 1964, 1965).

\section{METHOD}

Twenty-four Charles River strain rats were used. All animals shared common parentage; 12 pups composed each of two litters. The pups were raised with the mother in Plexiglas breeding cages ( $34 \times 20 \times 17 \mathrm{~cm}$ with a grated top). They were maintained on a $12 \mathrm{~h}$-light $/ 12 \mathrm{~h}$-dark cycle. The ambient noise level of the colony room was $62 \mathrm{dBA}( \pm 2 \mathrm{dBA})$ as measured with a Bruel and Kjöer (B \& $K$ ) sound-level meter. Between ages 10 days and 14 days, the pups were gradually acclimated to being separated from the mother for a $3 \mathrm{~h}$ period. The pups were weighed daily, and on Day 14 , they were assigned to one of three groups matched according to mean weight gains for the 5-day acclimation period.

The animals in the two experimental groups were placed in a $23 \times 28.5 \times 23 \mathrm{~cm}$ wire cage in a standard IAC $401 \mathrm{~A}$ chamber, and they were exposed daily to $3 \mathrm{~h}$ of continuous narrow-band

The principal results of this study were presented to the 99th Meeting of the Acoustical Society of America, April 1980, Atlanta, Georgia. Correspondence should be sent to W. A. Wilbanks, Department of Psychology, University of Georgia, Athens, Georgia 30602. noise for 30 days. The $3 \mathrm{~dB}$ bandwidth of the noise was $100 \mathrm{~Hz}$, centered at $8 \mathrm{kHz}$. The level of noise was $80 \mathrm{dBA}$ for Group 1 and $100 \mathrm{dBA}$ for Group 2. The spectrum levels of the noise for the two experimental groups were approximately $60 \mathrm{dBA}$ and $80 \mathrm{dBA}$, respectively. The noise was obtained by passing the output of a Grason-Stadler noise generator through two Krohn-Hite band-pass filters and a PAR tuned amplifier. The output of the tuned amplifier $(Q=100)$ was then fed to a Hewlett-Packard 450A amplifier and a 50-W McIntosh power amplifier. The transducers were two Jansen coaxial Sigma speakers and a Realistic tweeter wired in parallel. The level of the noise was continuously monitored with a B \& K 2606 measuring amplifier using a B \& K .25-in. microphone. The microphone was situated in the IAC booth such that it was oriented to give a randomincident open-field response. The spectrum of the noise output from the speakers was measured with a HewlettPackard wave analyzer. Crowley and Hepp-Reymond (1966) have determined, using a cochlear potential method, that the frequencies in this noise band are audible by age 9 days, the rat's hearing reaching adult sensitivity in this frequency band by age 15 days. The center frequency of $8 \mathrm{kHz}$ was chosen because it is a point of maximum sensitivity for the rat (Kelly \& Masterson, 1977).

The animals in the control group (Group 3) were placed in a similar cage in a room with an ambient noise level identical to that of the colony room, $60 \mathrm{dBA}( \pm 2 \mathrm{dBA})$. Before weaning at age 23 days, each animal was individually removed from the home cage and placed in the appropriate acoustic environment for the $3 \mathrm{~h}$ session. After weaning, the animals were observed in groups. The pups were weighed daily using an Ohaus triple-beam balance.

Behavioral observations for each of the following classes of behaviors were made, using Altman's (1974) focal observation method, during the first and last $15 \mathrm{~min}$ of each of the 3-h daily sessions: grooming, locomotion, play, aggression, sleep (including yawning and snuggling), and emotionality (defecation). During the last 3 days of the experiment, open-field measures of locomotion and emotionality (defecation) were taken in a $90 \times 90 \times 7.5 \mathrm{~cm}$ open field. The field floor was white and marked off into $15-\mathrm{cm}$ squares in black; the sides were black, and a wire mesh was placed on the top.

All animals were sacrificed within $30 \mathrm{~min}$ after the final observation period. Stomachs and adrenal glands were removed and prepared using the procedures described by Galvin and Mikhail (1976). Adrenal glands were weighed with a Sartorius balance, and stomachs were visually scanned for ulceration.

\section{RESULTS}

For statistical analysis, the behavioral measures were 
grouped into 5-day periods, and a two-way analysis of variance (ANOVA) (litter by treatment) was performed for each behavioral category for the first 15 -min observation period of each session. When significant effects were found, a post hoc Newman-Keuls test was performed to isolate the source of variability. For the last 15-min observation period of each session, the variability within groups was so great that the required assumption of homogeneity of variance was violated. Thus, a Friedman two-way ANOVA by ranks was performed on the data from the last 15-min period. The results are summarized as follows.

\section{Grooming}

Animals in both the 80-dBA and 100-dBA experimental groups groomed more than animals in the control condition $[F(2,30)=79.05, p<.01]$. A post hoc Newman-Keuls test revealed no differences between the two experimental groups, but highly significant differences were found between the control animals and both experimental groups $(p<.01)$. A Friedman's test showed a significant treatment effect between the controls and the experimental animals for the last $15-\mathrm{min}$ observation period $\left[\chi^{2}(2)=9.25\right.$, $\mathrm{p}<.01]$. There was no significant difference between frequency of grooming on successive days.

\section{Locomotion}

Animals in both experimental groups were more active than animals in the control group during the first $15-\min$ period $[F(2,30)=14.7, \quad p<.01]$. A post hoc Newman-Keuls test showed highly significant differences $(p<.01)$ between the controls and each of the two experimental groups. These differences had disappeared by the final 15-min observation period. Again, there was no significant difference between day-to-day measures of locomotion.

\section{Sleep}

Animals in the experimental groups slept less than animals in the control group during the first observation period $[F(2,30)=30.63, p<.01]$. A post hoc Newman-Keuls test for the first observation period showed no difference between the two experimental groups, but highly significant differences $(p<.01)$ between the experimental and control animals. Again, these differences had disappeared by the last 15-min observation period. There was no significant difference between daily measures.

\section{Emotionality}

The number of boluses was counted at the end of each experimental session. The data were grouped into 5-day blocks and analyzed by a two-way ANOVA. Although the animals in the experimental groups tended to defecate more than the control animals, this difference was not statistically significant. There was no statistically significant difference between day-to-day measures.

Measures of locomotion and emotionality in an open field were taken during the final 3 days of the experiment. Since the first open-field trial was for habituation, only data from the second and third trials were analyzed. All main effects for locomotion, as well as all interactions, were significant $(\mathrm{p}<.01)$. However, the Litter by Noise by Day interaction was disordinal, as was the Noise by Litter interaction. All other interactions were ordinal. Thus, little can be said about the effects of noise per se on open-field locomotion. Emotionality was assessed in terms of number of boluses deposited. Again, a three-way ANOVA (noise treatment by litter by day) was performed. The main effects of noise and litter were found to be significant $(p<.01)$, as were all interactions except Litter by Day. The three-way interactions and the Noise by Litter interaction were disordinal.

Body weight was measured daily. For statistical analysis, weight gains were grouped into 3-day blocks, and a two-way ANOVA (noise treatment by litter) was performed. The main effect of noise treatment was nonsignificant. The grand mean weight gains per group per 3-day block at the close of the experiment were: controls $=25.28 \mathrm{~g}, 80-\mathrm{dBA}$ group $=26.30 \mathrm{~g}$, and $100-\mathrm{dBA}$ group $=24.88 \mathrm{~g}$. Since daily variations were large, a Friedman's two-way ANOVA by ranks was performed; the treatment effect, in this case, only approached significance $\left[\chi^{2}(2)=4.98, p<.10\right]$.

Originally, adrenal/body-weight ratios were to be analyzed. A Spearman's rho showed a -.12 correlation between adrenal and body weights. For this reason, only adrenal weights were compared. A two-way ANOVA showed no significant differences between the control and experimental animals, although grand means suggested a slight difference (controls $=39.74 \mathrm{mg}, 80 \mathrm{dBA}$ $=39.41 \mathrm{mg}, 100 \mathrm{dBA}=42.19 \mathrm{mg}$ ). A Friedman's test showed that the treatment (noise) effect only approached statistical significance $\left[\chi^{2}(2)=4.75, p \leqslant .10\right]$.

Stomach ulceration was clearly seen in only one animal, a female from the first litter who had been exposed to the 100-dBA noise. There were no statistically significant differences in $\mathrm{pH}$ levels of stomachs between or within groups. All stomachs were within normal acidity limits.

\section{DISCUSSION}

The most general finding was that animals in the experimental groups were more active during noise exposure than the control animals. This effect was most pronounced during the initial $15 \mathrm{~min}$ of exposure. The animals in the experimental groups showed higher rates of grooming, playing, and locomotion, and correspondingly lower rates of sleep (and sleeprelated behaviors) than the control animals. With the exception of grooming, the increased level of activity for the experimental groups during the first $15 \mathrm{~min}$ of daily noise exposure had dissipated by the end of the 3-h session. In short, the main 
effect of noise exposure was to initially activate behavior; by the end of the 3-h exposure period, the experimental animals had habituated to the noise and did not differ from the control animals. There were no statistically significant differences between the two experimental groups. There were no statistically significant differences between the experimental and control animals in the frequency of aggressive or emotional behaviors during noise exposure. There was no day-to-day habituation; nor was there any day-to-day carry-over of the activating effects of noise.

The most pronounced effect of noise exposure was seen in grooming behavior. In the case of grooming, there was no response habituation during the $3 \mathrm{~h}$ exposure period. This finding is in agreement with an earlier study by Smiley and Wilbanks (Note 1), in which young rats were exposed to an octave-band noise centered at $8 \mathrm{kHz}$ at intensities of $90 \mathrm{dBA}$ or $100 \mathrm{dBA}$ for $3 \mathrm{~h} /$ day for 30 days. Fallon (1979) also found an increase in grooming behavior in the adult rat exposed to a 90 $\mathrm{dBA}$ broadband noise.

The finding of no statistically significant differences in emotionality between experimental and control animals is interesting, since noise does appear to act as a source of arousal during the early part of the exposure period. Although the experimental animals differed from the control animals with respect to emotionality in an openfield arena, the data do not permit any strong inference about the effects of daily noise exposure per se on open-field behavior in the developing rat.

Astrálága et al. (1975) reported that mice exposed to $90-\mathrm{dB}$ noise for either 3 or $8 \mathrm{~h} /$ day for 50 days (noise exposure starting at either age 2 days or 15 days) showed significantly smaller weight gains than control mice. The results of the present study do not confirm this finding for the young rat. Although there was a tendency for the animals in the experimental groups to show smaller weight gains, these differences were not statistically significant. Sackler, Wittman, Bradshaw, and Jurtshuk (1959) have reported that adult rats exposed to $110-\mathrm{dB}$ noise show increases in adrenal gland size, which Sackler et al. take as an indicator of a noise-induced stress reaction. We found no differences in adrenal gland weight between our experimental and control animals. It would appear that daily noise exposure at the level employed in our study is not a sufficient stressor to induce changes in body weight or adrenal size in the developing rat. Peptic ulceration is another physiological indicator of stress reaction (Paré, 1964, 1965). Clear ulceration was seen in only one of our animals; this animal was in the $100-\mathrm{dBA}$ group. Although it is interesting to note that this one animal had one of the largest adrenal glands, daily noise exposure at the levels we employed did not result in statistically significant differences between our experimental and control animals in incidence of stomach ulceration.

The major conclusions of this study are as follows: (1) The main effect of noise exposure ( $80 \mathrm{dBA}$ or $100 \mathrm{dBA})$ on the young rat is to increase the incidence of such activities as grooming, playing, and locomotion and, correspondingly, to reduce time spent sleeping during initial periods of noise exposure. (2) Behavioral habituation to noise occurs during extended periods $(3 \mathrm{~h})$ of noise exposure. No evidence of day-to-day habituation was found. (3) High-level noise seems to activate behavior, the activating effect disappearing during prolonged exposure. This activating effect of noise does not carry over from one day to the next. (4) No evidence of increased levels of aggression or emotionality, or of stress-related physical developmental changes, was found in the young rat as a result of daily hightevel noise exposure.

\section{REFERENCE NOTE}

1. Smiley, C. S., \& Wilbanks, W. A. Noise and behavior: An explanatory study. Unpublished study, University of Georgia, 1979.

\section{REFERENCES}

Altman, J. Observational study of behavior: Sampling methods. Behaviour, 1974, 49, 227-266.

Astrálága, M. E., Carvalho, G., \& Jiminez, B. [Behavioral effects of noise of $90 \mathrm{~dB}$ applied to mice during early development.] Revista Latinoamericana de Psicologia, 1975, 7, 237-258.

BARNETT, S. A. The rat: A study in behavior. Chicago: University of Chicago Press, 1975.

Bolles, R. C., \& Woods, P. J. The ontogeny of behavior in the albino rat. Animal Behaviour, 1964, 12, 427-441.

Crowley, D. E., \& Hepp-Reymond, M. C. Development of cochlear function in the ear of the infant rat. Journal of Comparative and Physiological Psychology, 1966, 62, 427-432.

FAllon, J. H., JR. The effects of inescapable noise and inescapable shock on subsequent response acquisition: $A$ test of the helplessness hypothesis. Unpublished doctoral dissertation, University of Georgia, 1979.

Galvin, G. B., \& Mikhail, A. A. Stress and ulcer etiology in the rat. Physiology \& Behavior, 1976, 16, 135-139.

Groн, L. S. The effects of 2 litter sizes and 2 levels of noise during infancy upon adult behavior in the white rat. Dissertation Abstracts, 1966, 27, 598-599.

Kelly, J. B., \& Masterson, B. Auditory sensitivity of the albino rat. Journal of Comparative and Physiological Psychology, 1977, 91, 930-936.

PARE, W. P. The effect of chronic environmental stress on stomach ulceration, adrenal function, and consummatory behavior in the rat. Journal of Psychology, 1964, 57, 143-151.

PARÉ, W. P. Stress and consummatory behavior in the albino rat. Psychological Reports, 1965, 16, 399-405.

Sackler, A. M., Wittman, A. S., Bradshaw, M., \& JuRTShuK, J. P. Endocrine changes due to auditory stress. Acta Endocrinologica, 1959, 31, 405-418.

SLONAKER, J. M. The normal activity of the albino rat from birth to natural death. Journal of Animal Behavior, 1959, 2, 20-42.

Small, W. S. Notes on the psychic development of the young rat. American Journal of Psychology, 1899, 11, 80-100.

WEISS, J. M. Effects of coping responses on stress. Journal of Comparative and Physiological Psychology, 1968, 65, 251-260.

(Received for publication December 2, 1981.) 